Sonne Cases treated with Sulphanilamide.-Twenty-nine cases were treated; the average duration of stay in hospital was 23.8 days, while the average number of days before becoming bacteriologically negative was 13.9 . These cases were divided into 9 acute cases and 20 convalescent carriers.

Sonne Cases-No Chemotherapy.-Fifty-seven cases were treated; the average duration of stay in hospital was 19 days, while the average number of days before becoming bacteriologically negative was 9.5 . These were divided into 18 acute cases and 39 convalescent carriers.

\section{Biochemical Findings}

Sulphaguanidine.-Blood concentrations usually varied from $3 \mathrm{mg}$. per $100 \mathrm{c.cm}$. to a trace, but in one case $9 \mathrm{mg}$. was found, in 2 cases $8 \mathrm{mg}$., in 1 case $7 \mathrm{mg}$., and in one other case $6 \mathrm{mg}$. per $100 \mathrm{c.cm}$. The concentration in faeces varied from a trace to as high as $10,000 \mathrm{mg}$. per $100 \mathrm{c.cm}$. At the beginning of the series leucocyte counts were done as a routine in each case, but as these were invariably normal this examination was discontinued.

Sulphanilamide.-Blood concentrations were lower than in the case of sulphaguanidine-treated cases, the highest concentration in the blood being $3.3 \mathrm{mg}$. and the lowest $0.1 \mathrm{mg}$. per $100 \mathrm{c.cm}$. In the main they varied between 1 and $2 \mathrm{mg}$. Concentrations in the faeces varied between a trace and $840 \mathrm{mg}$. per $100 \mathrm{c} . \mathrm{cm}$., the average being between 300 and $400 \mathrm{mg}$.

\section{Toxicity of Drugs}

In no case treated with either sulphaguanidine or sulphanilamide was any evidence of toxicity observed, judged by the standards of nausea, cyanosis, vomiting, pyrexia, rash, or haematuria. The urine was examined every second day for blood and albumin, but this practice was later reduced to twice weekly on account of lack of toxic symptoms. Older patients were also questioned with regard to any disagreeable effects, but these were remarkable by their absence.

\section{Gastro-enteritis in Infants}

Four cases were treated with sulphaguanidine; 3 of these patients died without any improvement in the stools or in the general condition. All were male babies, varying in age from 1 to 2 months and presenting varying degrees of dehydration, with frequent loose, green, and offensive stools from which no specific organism was obtained. The dosage used was $3 \mathrm{~g}$. during the first 24 hours as a loading dose, followed by $2 \mathrm{~g}$. daily for 4 days, but in none of the cases did the concentration in the blood exceed $0.8 \mathrm{mg}$. per $100 \mathrm{c.cm}$., although the concentration in the faeces went as high as $25,000 \mathrm{mg}$. We can only conclude that the dehydration and the frequency of the stools were so pronounced that the drug had no time to be absorbed and was passed rapidly through the intestines.

\section{Paratyphoid B Fever}

Eight cases treated with sulphaguanidine were taken, varying in age from 3 months to 53 years. Sulphaguanidine had no effect on the stools, which remained positive throughout the course and for a considerable time afterwards, although in two cases a distinct improvement in clinical condition was noted. These patients were exceedingly listless, with marked lose of appetite, but within 48 hours of starting treatment with sulphaguanidine their general condition had greatly improved. The dosage varied from $5.25 \mathrm{~g}$. daily for 6 days to a maximum of $10.5 \mathrm{~g}$. daily for 14 days.

\section{Summary}

273 cases of bacillary dysentery treated in the City (Infectious Diseases) Hospital, Aberdeen, during 1941-2 are described, together with 4 cases of gastro-enteritis of infants and 8 cases of paratyphoid $B$ fever. Of the cases of bacillary dysentery 140 received no drug, 83 were treated with sulphaguanidine, and 50 had sulphanilamide.

The series receiving no chemotherapy were given 2 drachms of sodium sulphate night and morning for an adult and $1 \mathrm{drachm}$ night and morning for a child. Those receiving sulphaguanidine were given a 5-day course based on body weight, the initial loading dose during the first 24 hours being $0.5 \mathrm{~g}$. per kilo of body weight, followed by a maintenance dose of $0.1 \mathrm{~g}$. per kilo for the next 4 days. Those receiving sulphanilamide were given a dosage amounting to half the quantity of sulphaguanidine.

The tablets were powdered and administered in milk 4-hourly for the first 24 hours and 3 times daily for the next 4 days. Parenteral fluids were given intravenously in the form of $5 \%$ glucose-saline where necessary, and particular stress was laid on fluid intake by mouth -8 to 10 pints for adults and proportionately less for children.

The stay in hospital and the number of days during which the stools remained positive were reduced by half in the sulphaguanidinetreated cases as compared with those receiving no chemotherapy, except in the case of Sonne convalescent carriers, in which both the stay in hospital and the number of days bacteriologically positive were slightly increased. In the sulphanilamide-treated cases both the stay in hospital and the length of time during which stools remained positive were increased, but this may be accounted for by the small dosage of drug and by the small number of cases treated.

Neither sulphaguanidine nor sulphanilamide produced any toxic symptoms or disagreeable effects.

4 cases of gastro-enteritis and 8 cases of paratyphoid B were treated with sulphaguanidine without any improvement.

I am indebted to Dr. Prescott of the Wellcome Foundation, who very kindly made available the necessary supplies of sulphaguanidine; and wish to thank Dr. John Smith, Director of the City Hospital Laboratory, for his interest and co-operation in this investigation.

\section{REFERENCES}

Anderson, D. E. W., and Cruickshank, R. (1941). British Medical Journal, 2, 497. Brewer, A. E. (1943). Ibid., 1, 36.

Bulmer, E., and Priest, W. M. (1942). J. R.A.M.C., 79, 277.

Buttle, G. A. H., et al. (1938). Biochem. J., 32, 1101 .

Canizăres, O., and Morris, G. E. (1941). Arch. Derm. Syph., Chicago, 44, 873. Fairley, N. H., and Boyd, J. S. K. (1942). Lancet, 1, 20. - (1943). Trans. roy. Soc. trop. Med. Hyg., 36, 253.

Firor, W. M., and Jonas, A. F. (1941). Ann. Surg., 114, 19. Iall, and Poth, E. J. (1941). Ibid., 114, 663.

Hall, W. A. (1941). New Orleans med. Surg. J., 94, 283.

Henderson, J. L. (1943). British Medical Journal, 1, 410.

Levi, J. E., and Willen, A. (1941). J. Amer. med. Ass., 116, 2258.

Lyon, G. M. (1941). Ibid., 116, 2440.

arshall, E. K., jun., Bratton, A. C., White, H. J., and Litchfield, J. T., jun. (1940). Johns Hopk. Hosp. Bull., 67, 163.

Roblin, R. O., jun., and Winnek, P. S. (1940). J. Amer. chem. Soc., 62, 1999.

\section{TECHNIQUE OF INTRAVENOUS DRIP TRANSFUSION IN INFANTS \\ BY}

D. MacCARTHY, M.D., M.R.C.P., D.C.H.

Late Registrar, Hospital for Sick Children, Great Ormond Street

The technique of intravenous drip transfusion, or venoclysis, was first applied to the treatment of infants about ten years ago, since when it has established itself as the most effective method of combating severe dehydration due to infantile diarrhoea and vomiting or for the postoperative administration of fluids in babies and small children. But it is much more difficult to carry out than in adults, has more risks, and provides an arduous task for the nursing staff, on whose energies and competence the success of the method chiefly depends. Unfortunately, owing to the frequency with which things can go wrong, it is apt to be regarded as a method that demands a party of experts to run it. It is true there is a real danger of overloading the system with fluid, and judgment in this matter requires experience; but it is as often as not the accumulation of small faults and mishaps, rather than more serious ones, that determines the success or failure of the undertaking. The object of this paper is to discuss the causes of failure and their remedy and to put forward some general principles for running continuous intravenous transfusions in infants with efficiency and safety.

\section{The Technique Normally Adopted}

The anterior saphenous vein at the ankle is chosen, as it is very constant in position and has definite surface markings. It lies on the anterior surface of the tibia, running upwards and slightly backwards midway between the tendon of tibialis anticus and the internal malleolus of the tibia, both of which can be felt. It is often visible in thin babies or may be made to stand out, and it is plainly visible in most adults, in whom its position and course may be easily examined.

The diameter of this vein in a 3-months-old baby is between 1 and $2 \mathrm{~mm}$., and although it will stretch to slightly more than this it is difficult to insert a cannula into it of greater thickness than $2 \mathrm{~mm}$. Various types of cannula are used to meet the case, such as a large-sized hypodermic needle with the bevel 
cut off, a ureteric catheter (Wilmers, 1938), a hypodermic needle covered by a closely fitting length of ureteric catheter, a smallsized Hamilton Bailey needle, or the needle specially designed for the purpose by Bateman, with an inner cannula which can be removed and cleaned should it become blocked.

The foot and leg are firmly fixed by strapping to a padded splint applied to the outer side of the leg. The foot is fixed in a position of slight plantar flexion (Fig. 1). The skin between the internal malleolus and the tendon of tibialis anticus is anaesthetized with local anaesthetic: $0.5 \mathrm{c.cm}$. of $1 \%$ novocain is usually enough for this, but another $0.5 \mathrm{c.cm}$. may be injected more deeply. A transverse incision about half an inch long is then made at right angles to the axis of the vein at the level of the internal malleolus. The vein, which may be difficult to see if there is much oozing, is identified by its bluish or pinkish colour, and is dissected free from its fascia so that two ligatures, about a quarter of an inch apart, can be passed under it. The distal ligature is tied immediately.

The vein is opened by an oblique or transverse scissor-cut, as in the technique for adults, and the cannula inserted and tied in with the proximal ligature. Obviously in such a tenuous vessel some care is required to cut a hole big enough to admit the cannula and yet not snip the vein clean in half. It is this, and finding the vein, that constitute the chief difficulty of the operation.

One c.cm. of normal saline should now be injected through the cannula. If the latter is in the vein the saline will go in with the lightest pressure on the plunger; but if it is in the sheath of the vein, or in the soft tissues or some fascial tissue that was mistaken for a vein, pressure will be required and a lump will appear under the skin. All being well, the incision is closed by one stitch, and the tubing carrying the transfusing fluid from the vacoliter is connected to the cannula by a wellfitting adapter nozzle and secured in position by strapping; the flow of fluid is then started, the rate being controlled by a screw clamp and drip connexion.

\section{Some Dangers, Difficulties, and Mistakes}

1. Severe or Fatal Collapse at the Start.-An intravenous drip should never be regarded as an emergency. It may be very urgent and a life-saving measure in an acutely dehydrated infant, but often in such cases a condition analogous to shock is present, due to anhydraemia and toxaemia, and the process of setting up the drip, however skilfully done, may be more than the infant can stand. There is no case that will not be better off in these circumstances by being given a hot bath, put into a warmed bed, and left severely alone for one or two hours. At the end of this time it will probably be able to stand such intervention as is necessary to start the transfusion.

2. Excessive Time Spent in Setting up the Drip, with Consequent Exhaustion of the Infant and Deterioration of its General Condition.-The baby may be relieved of much strain by dividing the whole process into three stages. When it is decided to give an intravenous drip (i.e., on admission or when examining the infant in the ward) a time should be chosen which suits the ward and the doctor (within a few hours, of course ; there is never more urgency than this); but the preliminaries of splinting, cleaning, and tying the limb should be carried out forthwith. The baby is then left in peace for an hour or more, and may get to sleep in the ensuing interval until the time of the operation. When that time comes it is rested, and part of the procedure is already completed.

In the second stage the instruments, vacoliter, etc., which have been prepared are brought to the very last degree of readiness at the bedside, the infant as yet being completely undisturbed. The vacoliter must be suspended, tubing filled and saline dripping from the cannula, aneurysm needle threaded, stitch ready, and small strips of strapping available for fixing the cannula and tubing in position. The tightness of the adapter fittings must be tested, also the points of the scissors. To insert the cannula it is necessary to cut half-way through a vein which may be only $1 \mathrm{~mm}$. thick, so it is important to make sure that the tips of the scissors will do their job.

In, the third stage the bedclothes are gently lifted back, exposing the limb all ready, and the dissection of the vein is begun. When quickly and neatly done the baby suffers very little fatigue, and may even sleep through it. But if the three stages described are made one procedure and there are any minor mishaps or delays, as there often are, the total time spent on the job is much longer for the baby, and in the end an hour or more may elapse before it is once again left in peace. By this time it may be very exhausted.

As to the actual dissection of the vein, only practice can bring speed, but it is worth while for the inexperienced to note that the vein is more easily seen when a.local anaesthetic is injected into and deep to the subcutaneous tissue, as its blueness then contrasts with the pale injected tissues and oozing is diminished. About $1 \mathrm{c.cm}$. of $1 \%$ novocain in all may be used. If the subcutaneous tissue is widely split at right angles to the incision by opening the points of the scissors, it can be identified at once, but it is less and less easily discerned when the tissues become blood-stained from frequent swabbing and tentative probing. In plump babies there need be no fear of severing the vein in cutting through subcutaneous tissue, as it lies well down on the deep fascia. It is easier to insert the cannula into very small veins if the stylet is in, as this projects beyond the end of the cannula and, being smaller, can be got into the vein first ; the cannula can then be slid along the stylet till it also lies in the vein.

3. Venous Spasm.-It is not uncommon for the drip to stop immediately after it is set up or to run excessively slowly at the start. Attempts to correct it there and then only lengthen the time of the whole operation and add to the exhaustion of the child. The temptation to continue manipulations with or syringing through the cannula must be resisted. If the limb is warmed up by hot-water bottles and the whole thing left alone, the drip will nearly always start spontaneously and speed up by itself. Relaxation of venous spasm may be the reason.

4. Clotting.-A double cannula, of which Bateman's needle (Field et al., 1943) is an example, is the only safeguard against this fault. If the inner cannula becomes blocked it can be thoroughly cleaned and replaced without trouble. It is therefore essential to get an outer cannula into the vein first: it may be a tight fit, but it can be done in all but the very smallest veins. One of the causes of clotting has its origin at the time of setting up the drip. Thus, when the outer cannula is inserted into the vein blood may flow back along it. If there is any delay in starting the flow of saline this blood will begin to clot; then when the inner cannula is inserted through this clot a small plug will block the end of it. Although this plug may be driven out at once, any particle remaining will form the starting-point of a firmer clot later on. Therefore a stylet should always be placed in either cannula when saline is not flowing through it even for a few minutes, and the stylet should be in the outer cannula at the time it is introduced.

5. Splinting the Limb.-Nearly all other troubles-for example, irregular dripping, leaking, damage to vein, etc., mentioned below-are due to the limb not being properly immobilized or the fixation of the cannula and tubing being insecure. Splints of several sizes must be available. When an ankle vein is used the splint should project well beyond the

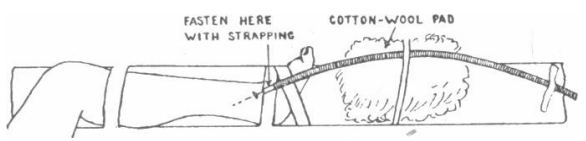

Fig. 1.-Right way. Long splint; tubing supported and approaching the cannula at the right angle, without flexion.

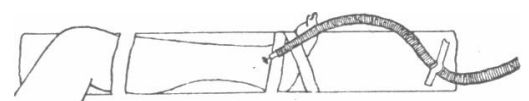

FIG. 2.-Wrong way. Short splint; flexion on tubing, with spring-like strain transmitted to vein.

foot and should have little padding. The foot must be fastened to it most firmly with strapping next the skin. Elastoplast will not do, and a heavily upholstered splint or the limb swathed in cotton-wool and bandages is worse than useless. When properly set up, the splint, leg, cannula, tubing, and dressing, held together by as many strips of strapping as required, form one firm structure. The baby can wave its leg about or be taken out of bed for nursing or lie on either 
side-a great advantage, for it sleeps much better on its side. The most important thing is that the splints should be long enough to project 8 to $12 \mathrm{in}$. beyond the foot, so that the tubing leading to the cannula in the vein may be fastened at the far end of the splint and then have a straight run up towards the vein (Fig. 1). If it is fastened close to the foot the tubing will have flexion on it, the spring-like action of which will be transmitted to the cannula in the vein, and the strain on the wall of the vein may be considerable (Fig. 2). A pad of cotton-wool should support the weight of the tubing and give it the natural curve required to bring it nicely to the vein (Fig. 1). Sometimes the tubing is left unfastened in the most haphazard way, in which case it waggles to and fro and may tear the vein, so that the transfusion becomes a continuous subcutaneous, not an intravenous, drip. The rate of flow varies considerably if the cannula is loosely held in position, as any movement of the foot or tubing may cause it to kink the vein. Also, the endothelium may be damaged and thrombosis occur. A small stitch, through skin only, just distal to the incision, may be used to tie the cannula in position, and is very effective in preventing any lateral or pulling and pushing movement of the cannula in the vein. When the foot is really securely held the baby feels no pain and does not want to move it. But when things are loose its wriggling causes pain and it tries to work the foot looser still. Leaking may then occur between the adapter nozzle and the cannula. This is another cause of irregularity in the rate of the drip, and the discrepancy between the recorded amount run in and the amount the child has really received may be serious. The arm is much easier to control, and for this reason drips in the antecubital veins generally run smoother and longer than others. But these veins may be difficult to find in fat babies unless they can be seen.

The cephalic vein at the wrist, which corresponds anatomically to the anterior saphenous at the ankle, is serviceable in all but the tiniest babies. It runs midway between the styloid process of the radius and the tendon of extensor carpi radialis. The hand should be splinted palm downwards.

\section{Complications}

Sepsis should never occur; but it does. The frequency of its occurrence is directly proportional to the amount of interference there has been in the course of the continuous drip. The case that runs smoothly, for several days even, hardly ever gets infected. But when the dressing is frequently lifted and many readjustments are made infection is apt to creep in. Thrombophlebitis is common but very rarely proceeds to suppuration. An abscess sometimes forms, a week or more later, half-way up the calf. A low-grade infection of the incision is quite common. These complications respond well to appropriate measures, but, occurring in infants who are already much debilitated, should always be regarded seriously. Their prevention is embodied in the measures described for promoting smoother running of the drip.

Oedema.-Local oedema may be due to the strapping being too tight above the site of transfusion, to the drip being too fast, to tearing or thrombosis of the vein; or it may be the first sign of a developing general oedema. General oedema may be due to too much fluid, too much sodium, hypoproteinaemia, nephritis, sclerema, anaemia, vitamin B deficiency, or circulatory failure. Eucortone may also cause it (Ferrebee et al., 1939). With the exception of too much fluid, it is extremely difficult to distinguish clinically between these various causes of general oedema. In any case of general oedema or pulmonary oedema the drip must of course be discontinued at once.

Bronchopneumonia.-This is still regarded as the most serious and most frequent complication of gastro-enteritis, and the blame is often laid on the continuous intravenous drip. But it must be borne in mind that the majority of cases of infantile diarrhoea and vomiting are due to upper respiratory tract infection, and the infecting organisms may show various propensities for invading the lungs and bronchi in different epidemics and different seasons, regardless of whether continuous drips are given or not. However, there is no doubt that nursing a baby for long periods on its back or maintaining a high salt content in the transfusing fluid does favour pulmonary stasis and oedema, leading to infection, whereas nursing it on its side and with moderate salt content in the fluid does not.

Petechial Rashes.-These occasionally occur in the later stages in cases of gastro-enteritis that have been given several intravenous drips. They begin as very fine speckled petechiae, chiefly on the trunk, and may develop into ecchymoses or large haemorrhagic taches. They are presumably due to capillary damage. The nature of this is uncertain, but it is not scorbutic, as vitamin $\mathrm{C}$ does not prevent it or cure it; nor is it likely to be "toxic," as these rashes do not occur at the most toxic stage of the illness, which is usually the beginning. The probable explanation is the strain imposed on the capillary endothelium by the frequent disturbances of blood volume and alterations in blood chemistry occurring during repeated transfusions. The prognostic significance is not as grave as that of haemorrhagic rashes in general infections, but the outlook is usually very bad for other reasons.

\section{Control over Fluid Input}

It has already been mentioned that giving too much fluid constitutes a major risk in the application of the technique of intravenous transfusions to infants. The following general rules provide a reliable safeguard against this danger and will be found to make for good results.

1. The approximate quantity of fluid required in 24 hours must be calculated in advance and put down in writing together with the child's weight as a check for all to see.*

2. The rate at which this fluid is to be given must be expressed not as drops per minute but as ounces (or cubic centimetres) per hour. This needs special emphasis, for the size of a drop varies with the speed at which it falls and the shape of the dropper; also, the rate of dripping is apt to vary while the observer's back is turned, and a period of slow or rapid dripping may go unrecorded. Therefore even if specially calibrated droppers are used it is impossible by this means to foretell how much fluid will be delivered over a given period of time; the rate of the drip is much too variable. The nurse who is controlling the drip must find by trial and error the approximate rate which will deliver a given amount per hour, and periodically adjust it according to her own judgment to keep the input per hour within such limits.

3 . There must be reasonably accurate and reasonably punctual hourly recording of the amount run in. An exceptionally large or small input in one hour can then be corrected in the next.

4. The amounts per hour should be added up as the day goes on; it is then easy to see how far the total for the 24 hours is going to exceed or fall short of the required amount, and adjustment of the hourly quantity can be made accordingly. Fluids by mouth must of course be included in the reckoning. $\dagger$ It is more practical to express intravenous fluid in ounces than in cubic centimetres, as this is the unit by which a baby's fluid intake is normally measured and a unit with which all nurses are familiar. The reading of these hourly quantities on the scale is easier and more accurate if the vacoliter or flask is tall and of small diameter. The Baxter type is not very suitable. In practice it will be found that measurement to within a quarter of an ounce is quite easy on the E.M.S. transfusion bottle, and it is not necessary to try to be more accurate than this.

5. Strength of Saline to be Used.-It is now widely accepted that the continuous transfusion of normal saline carries with it the danger of producing hydraemia and oedema, as the infant's powers of excreting surplus sodium chloride are limited. Solutions of approximately half-normal saline, on the other hand, are adequate for replacing lost base in any case of diarrhoea and vomiting, and have not this danger of overloading the body fluids with salt.

6. Occasions for Extra Caution.-(i) When any degree of circulatory failure is present much greater caution must be used if overloading the heart is to be avoided. (ii) Babies with "toxaemia," whether it be from "alimentary intoxication," pneumonia, otitis media, or any other infection, have difficulty in retaining fluid given parenterally and in adjusting the balance between intracellular and interstitial fluid. They are liable to remain in a state of chronic dehydration even when given full quantities to cover fluid loss. By contrast the non-toxic dehydrated baby-for example, a case requiring fluid after operation or a pyloric stenosis-when given correct amounts will adjust its fluid balance with ease. If the infection can be overcome the same may be expected of the " toxic " baby; but pushing fluids or attempting to adjust blood chloride levels, etc., by varying strengths of saline is unlikely to achieve anything so long as this persists.

* The actual quantities and rates of transfusion, according to weight of baby, are discussed by Field et al. (1943).

$\dagger$ All these points are embodied in the daily fluid chart advocated by Field et al. (1943). 


\section{Conclusion}

Nothing perhaps requires greater emphasis in this paper than that all these points concerning technique should be thorough!y understood by the nursing staff. Some of them may seem trivial, but it is only by constant attention to these details that this method of continuous intravenous drip transfusion will consistently give the good results which are justly claimed for it.

\section{REFERENCES}

Ferrebee, J. W. et al. (1939), J. Amer. med. Ass. 113, 1725. Field, C. E., MacCarthy, D., and Wyllie, W. G. (1943). British Medical Journal, Wilmers, M. J. (1938). Proc. roy. Soc. Med., 31, 755.

\section{TRIGEMINAL NEURALGIA AT AN EXCEPTIONALLY EARLY AGE: CURED BY GASSERIAN ALCOHOL INJECTION}

WILFRED HARRIS, M.D., F.R.C.P.

Physician to Maida Vale Hospital for Nervous Diseases; Consulting Physician to St. Mary's Hospital

Paroxysmal trigeminal neuralgia-or, better, trigeminal tic -is usually a disease of the latter half of life, four-fifths of all cases starting within the three decades $41-70$ and more than one-third in the decade 51-60. Yet occasionally young people are attacked, for I have had more than twenty patients who began to suffer before the age of 21 -two of them at the age of 12 . The earliest hitherto recorded case in my knowledge is that of a boy aged 10 operated on by Mr. Barclay (1922) of Newcastle.

\section{Case History}

I have now to record the case of a girl who had been suffering since the age of 16 months from frequently repeated daily spasms of pain, lasting a few seconds only, and referred to the left lower jaw up to the ear. She was a Caesarean baby, weighing $9 \mathrm{lb}$. at delivery, and between the ages of 4 and 5 months had won no fewer than four prizes at baby shows. Yet her dentition did not start until she was 12 months old, and from the age of 16 months she began to have obvious pains with her teeth, paroxysms of a few seconds' duration occurring frequently during the day, and often waking her, screaming, at night. At first the neuralgic attacks seemed to affect both sides, until she completed her milk dentition at the age of 3 years - a year later than the average. Since then the attacks have been definitely limited to the left side, being referred along the lower jaw to the ear, and lasting a few seconds only.

She was first brought to me on July 3,1942, when less than $4 \frac{1}{2}$ years old, and on several occasions I witnessed the sudden attacks of pain, lasting only from a few seconds to a quarter of a minute, the child immediately afterwards becoming quite normal in behaviour. Radiographs of the mandible showed no bone or dental abnormality. She had previously been treated at Great Ormond Street Hospital, and drugs seemed to have no influence on the neuralgic spasms, so I decided on alcohol injection of the foramen ovale. This I attempted on Aug. 21 under preliminary rectal paraldehyde and then ethyl chloride inhalation. No co-operation with the little patient was possible by such a method, and the result was not good: anaesthesia of the third division was slight, if any, and freedom from pain lasted only a couple of days. Three other attempts were made under general anaesthesia in September and November, using the lateral route, without obtaining lasting trigeminal anaesthesia, though after the injection on Nov. 18 she had very few attacks of pain for ten days, then relapsing as before. On Dec. 9 I again injected under a general anaesthetic, using the anterior route in front of the coronoid process, and this time produced complete left trigeminal anaesthesia, after injecting 8 minims of $90 \%$ alcohol into the Gasserian ganglion. The neuralgic spasms died away within two days, and she has had no further signs of neuralgia up to the present time- - seven months after the injection-though some keratitis developed during the last week of December, with some temporary loss of the superficial corneal epithelium. She was taken into Maida Vale Hospital at once, and the keratitis cleared up completely under treatment, and the cornea now shows no sign of opacity or scar. With the exception of a mild attack of German measles while being treated for the keratitis she has remained perfectly well, and, though the trigeminal anaesthesia persists unaltered, the child does not appear to take notice of it, and is quite merry and bright.

\section{Comment}

As regards the prognosis, it is quite probable that the cure will be permanent, as I have found in numerous other similar cases in adults. There is a possibility of recurrence of neuralgia on the other side, for I have met with bilateral trigeminal tic in at least 100 cases, and its incidence, in my experience, seems to be between 4 and $5 \%$ of the total cases seen. Sometimes the neuralgia appears on both sides within the period of a week, but more often there is an interval of several years. One of my patients, a lady of 64 when I first saw her eighteen years ago, had suffered since the age of 12 with typical neuralgic tic on the right side of the face-that is, for 52 years. Gasserian injection cured that pain completely; but fifteen years later, when she was 79 , similar neuralgia attacked the left side, and I had to inject the left Gasserian ganglion also, thus numbing both sides of her face completely. Sixtyseven years therefore separated the onset of the neuralgia on the two sides. The left motor' root had recovered after the first Gasserian injection, as is usually the case, and therefore she had no jaw-drop after the second Gasserian injection.

The probability of bilateral pain probably increases with the length of duration of the disease, so that in the case of the child described above, whose pain was at first bilateral, there is a distinct possibility that the pain may recur at some future date on the right side.

As regards the aetiology of trigeminal tic, it is usually stated in medical and neurological textbooks that the cause is unknown. I have for many years been convinced that the cause is an infective neuritis of the trigeminal-nerve endings in the maxilla or mandible, in the large majority of dental origin, though occasionally secondary to antral infection. This view I have consistently taught, and have published on various occasions, with my reasons for this belief (Harris, 1926, 1937, 1940).

In the case of this little child, otherwise very healthy and not in the least degree of neurotic type, the acute onset of the neuralgia with commencement of her teething is most suggestive evidence of the close connexion between dental disturbances and the origin of trigeminal tic.

\section{REFERENCES}

Barclay, J. H. (1922). Brit. J. Surg., 9, 306.

Barclay, J. H. (1922). Bentgia and Neuritis, p. 162, Oxf. Med. Pub., London Harris, Wilfred (1926). Neuralgia and Neuritis, p. 162, Oxf. Med. Pub.,
(1937). The Facial Neuralgias, p. 25, Oxf. Med. Pub., London.

(1940). Brain, 63, 215.

\section{THE AVAILABILITY OF THE CALCIUM OF MILK BY}

KATHARINE H. COWARD, D.Sc.Lond. ELSIE W. KASSNER, F.I.C.

AND

\section{LETITIA W, WALLER}

(From the College of the Pharmaceutical Society, London)

The experiment reported here was carried out in response to criticism of our experiments published in this Journal (Coward, Kassner, and Waller, 1938). In the early experiments we had shown that rats fed on a diet resembling that of a poorerclass population and supplemented by liberal doses of codliver oil failed to produce normal calcification of the bones, but that the calcification was improved in proportion to the supplementary doses of a mixture of calcium and phosphate salts given. In fact, the highest dose of salt mixture produced as high a percentage of ash as did a supply of milk ad lib. each day. It was not, however, from a comparison of results of these apparently excessive doses that we drew our conclusion of the relative availability of calcium from milk and from salts, but from the result of giving only $5 \mathrm{ml}$. of milk to one of the groups of rats. Unfortunately we had not determined the calcium content of the milk given, for this comparison was not the purpose of the experiment. Judging by the percentage of ash found in the bones, however, the milk apparently contained only $0.76 \mathrm{~g}$. of calcium per litre. Since the average calcium content of cow's milk is $1.12 \mathrm{~g}$. per litre, we thought it very unlikely that the sample we used could 